\title{
Bacteriological Profile of Healthcare Workers and Patients' Hands at Aga Khan University Hospital, Nairobi Outreach Centres
}

\author{
Martin Wanyama Wamalwa ${ }^{1,2 *}$, Kennedy Kuria Muna ${ }^{3}$, Geoffrey Omuse ${ }^{1}$, \\ Stanley Kang'ethe Kamwati ${ }^{2}$ and Revathi Gunturu ${ }^{1}$ \\ ${ }^{1}$ Department of Pathology and Laboratory Medicine, Aga Khan University Hospital, Nairobi \\ ${ }^{2}$ Department of Medical Laboratory Science Mount Kenya University, Kenya \\ ${ }^{3}$ Department of Medical Laboratory Science Muranga University of Technology
}

\begin{abstract}
Background: Hand hygiene is the precursor to improved health standards among healthcare workers and patients seeking outpatient services. Unhygienic hands may escalate the transmission of multi-drug resistance bacteria that poses serious pathological manifestation to the vulnerable and susceptible patients. The study aims at establishing the possible pathogen and susceptibility pattern of Staphylococcus aureus carried on hands of healthcare provider and their patients.

Methods: Cross sectional study design and random sampling of patients and convenient sampling of healthcare workers was carried out between May to August 2020 at Aga Khan University hospital Nairobi satellites. The participant's hands palm and finger tips imprints were made on Blood agar during sample collection. The antimicrobial susceptibility pattern of Staphylococcus aureus was established using Vitek-2 automated system.

Result: The study had 374 participants out of which 14\% were colonized by possible pathogens. The overall Staphylococcus aureus hand carriage prevalence $6.9 \%(26 / 374)$ isolated from healthcare provider and patient at outpatient facility. The methicillin resistant staphylococcal in this study was $0.56 \%$ (2/374) showing resistance to both Oxacillin and Cefoxitin. Healthcare workers are prone to colonization with possible pathogens as compared to patient P-value .049. Staphylococcus aureus isolates were all resistant to penicillin.

Conclusion: Hand hygiene mitigating measures in outpatient healthcare facilities should be sustained on the counts that $14 \%$ of possible pathogens in this study were isolated. Healthcare providers at the point of care in outpatient should strictly follow the hand hygiene protocols provided by WHO to curb the transmission of possible pathogenic bacteria.
\end{abstract}

Keywords: Bacteriological Profile, Susceptibility Pattern, Outpatient Point of Care, Healthcare Providers And Patients' Hands

\section{Introduction}

Hand hygiene is the precursor to improved health standards among healthcare workers and patients seeking outpatient services. Healthcare workers and patients are exposed to various microbial agents during triaging, physical examination and sample collection. Unhygienic hands may escalate the transmission of multi-drug resistance bacteria that poses serious pathological manifestation to the vulnerable and susceptible patients. ${ }^{[1]}$ The morbidity, mortality and the high frequency hospital revisits after treatment are of great concern worldwide.

Routine contamination of hands by bacteria through physical contact ends up cross infecting patients or inanimate objects in the immediate surroundings. Several important pathogens are endogenous microbes carried on body orifices including nares, ear canal and the body surfaces. ${ }^{[2]}$ It has been highlighted by various scientific authors that methicillin-resistant Staphylococcus aureus, Acinetobacter baumannii, vancomycin resistant
Enterococcus species and Enterobacteriaceae species ${ }^{[3,4]}$ are frequently implicated as the contact transmissible agents. Methicillin resistant Staphylococcus aureus and the methicillin susceptible Staphylococcus aureus pathogens ${ }^{[5]}$ have acquired huge attention globally and are now used as the indicators of multidrug resistance in a clinical setup.

Lack of hand hygiene products and the technologies to screen for hand carriage, high workload, inadequate staffs, patient overcrowding especially at outpatient reception areas, and lack of running water are the major contributors to non-compliance to hand hygiene. Therefore, investment in appropriate hand hygiene compliance measures is vital to reduce HAIs. However, unacceptable prevalence of below $50 \%{ }^{[6]}$ hand hygiene compliance is being recorded. The healthcare acquired infection caused by Staphylococcus aureus alone through hand contact is estimated to be between 15 to $46 \%{ }^{[7]}$ at ICU worldwide. In US for example, the study carried out by ${ }^{[8]}$ on hand carriage among prisoners was $24.9 \%$ of Staphylococcus aureus. 
The prevalence of transient bacteria transmitted through hands touch by healthcare workers in Africa was higher than most developed countries. For example, studies conducted among staffs working in hospitals and school children in South Africa, Nigerian and Egypt was 29\%, $29.9 \%$ and $34 \%$ respectively. ${ }^{[9,10]}$ Little information on bacteriological profile on hand of staffs working in clinical facilities and patients was found in East Africa region. The hurdle of knowing the bacterial strains found on the hands of healthcare providers and patients in outpatient settings remains unresolved. ${ }^{[11]}$

Hand screening of bacterial profile of clinical staffs and patients in outreach centres may help to reveal the most transmitted pathogens through hand contact. ${ }^{[2]}$ According to World Health Organization, hand washing protocols if utilized efficiently by healthcare practitioners during their course of work may curb the spread of both HAIs and community associated infection. More focus is on intervening, preventing and controlling HAIs risks at ICU to practice hand hygiene. Not much has been done to identify the hand carriage at outpatient facilities. This informs the concern of this study.

\section{Material and Methods}

The cross section study design and random sampling of patients' and convenient sampling of health care providers was carried out between May and August 2020. The samples were collected from Aga Khan University Hospital Nairobi outreach satellites centres on healthcare workers and patients attending these facilities.

\section{Sample collection}

Participants who consented to the study, their imprints of fingertips, nails, and palms of their hands was gently pressed onto $5 \%$ sheep blood agar medium in their respective working stations. Then the medium was sealed in biohazard zip lock bags and transported under the cold chain at $2-8^{\circ} \mathrm{c}$ in laboratory cooler boxes to reach microbiology laboratory with 8 hours of collection to microbiology laboratory.

\section{Sample Isolation and Identification}

The inoculated samples were acclimatized at room temperature then incubated at $37^{\circ} \mathrm{C}$ for 24 hours and checking for growth at frequency of 12, 24 and 48 hours for colonies formation. The identification of microbial isolates was done visually for colour, haemolysis and biochemical testing. Then Gram stain was performed to check for morphological characteristics. Subsequently, from the primary culture and single colony was sub cultured to get the pure culture of a single organism. The inoculum colony suspension sample from pure isolate of organisms was aseptically transferred to $3.0 \mathrm{ml}$ of sterile $0.45 \%$ saline using a sterile swab to prepare a homogenous organism suspension and standardized using the McFarland standard Scale 0.5 to 0.63 turbidity. The corresponding identification card for Gram positive organism and Gram negative was used respectively. These was then analysed using Vitek 2 compact system that employs a flourogenic method for organism identification and a turbidimetric method for susceptibility testing using 64 well cards.

\section{Antimicrobial Susceptibility Testing}

The antimicrobial susceptibility testing was performed after obtaining single pure Staphylococcus aureus organism. The GP-AST antimicrobial agents that were subjected to the isolate included; Benzylpenicillin, Trimethoprim/ Sulfamethoxazole, Erythromycin, Gentamicin, Tetracycline, Levofloxacin, Nitrofurantoin, Vancomycin, Clindamycin, Linezolid, Mupirocin, Oxacillin/ Methicillin, Cefoxitin Screen. This selection was based on Performance by CLSI standards for antimicrobial susceptibility testing guideline on staphylococci agents. Staphylococcus aureus isolates that showed resistance to cefoxitin or oxacillin, using Vitek 2 analyser was reported as methicillin/ oxacillin resistant. The analyser releases the results using the software for ID or AST to the laboratory information system (LIS) automatically. The accepted results for either the identification or sensitivity testing at confidence level above 95 probabilities was termed as excellent probability then a printable hard copy was acquired for filling.

\section{Quality Control}

The microbiological analyser was checked for the performance characteristic of precision and accuracy. The S. aureus (ATCC 25923), E. coli (ATCC 25922) and $P$. aeruginosa (ATCC 27853) were used as control organism before analysis was performed for isolates.

\section{Data Analysis and Presentation}

The association was calculated using the Chi-square at 0.05 confidence level by help of Statistical package for social science version 20 (SPSS).

\section{Ethical Consideration}

The letters of approval to carry out the study were obtained from Mount Kenya university medical school department of medical laboratory science and Aga Khan University Hospital IERC. Then the permission to carry out research was obtained from the Aga Khan University hospital Nairobi Outreach department and further obtained permit from National Commission for Science and Technology Institution (NACOSTI).

\section{RESULT}

The study found that the prevalence of bacteria was higher in healthcare providers $(18.5 \%)$ than the patients $(11.6 \%)$, 
as shown in Table 1. Based on gender, Staphylococcus aureus and CoNs were most prevalent in males (46.4\% and $35.7 \%$ respectively). For females, Staphylococcus aureus and CoNs were also most prevalent $(54.2 \%$ and $33.3 \%$ respectively) (Table 2). Based on age category, bacterial prevalence was higher for those aged 54-70 years (17.4\%) as presented in Table 3 .

On specific bacterial contaminations, Staphylococcus aureus were more prevalent in patients $(55.2 \%)$, followed by CoNs (34.5\%) and Streptococcus ssp (6.9\%). For healthcare workers, Staphylococcus aureus were also more prevalent (43.5\%), followed by CoNs (34.8\%), Pseudomonas spp (8.7\%) and Proteus mirabilis $(8.7 \%)$ (Table 4). For those aged 17 and below, Staphylococcus

Table 1: Bacterial prevalence per type of participant. aureus was the only prevalent bacteria. For age category 18-35 years, all bacteria were present, with Staphylococcus aureus most prevalent (40\%) and CoNs (36.7\%) (Table 5).

All samples for HCW were Methicillin-sensitive Staphylococcus aureus (MSSA) $(\mathrm{n}=10)$ with no sample being Methicillin-resistant Staphylococcus aureus (MRSA) $(\mathrm{n}=0) \quad$ (Table 6). The study found that 16 samples were MSSA and MRSA for patients; where MSSA $(n=14)$ and MRSA $(n=2)$ (Table 7). The study found that Benzylpenicillin was the most resistant followed by Trimethoprim/Sulfamethoxazole (26.9\%) and Erythromycin (15.4\%) and Clindamycin (15.4\%). Vancomycin, Tetracycline, Levofloxacin, Mupirocin, Linezolid, Gentamicin and Nitrofurantoin were the most sensitive (Table 8).

\begin{tabular}{|l|l|l|l|l|}
\hline & \multicolumn{3}{|c|}{ Presence of bacteria } & P value \\
\hline Type of participant & Yes & No & Total & \\
\hline Patient & $29(11.6)$ & $221(88.4)$ & $250(100.0)$ & .049 \\
\hline Healthcare provider & $23(18.5)$ & $101(81.5)$ & $124(100.0)$ & \\
\hline
\end{tabular}

*P value were determined by Chi-square test

Table 2: Bacterial profiles per gender.

\begin{tabular}{|l|l|l|l|l|l|l|l|l|}
\hline Gender & CoNs & $\begin{array}{l}\text { Staphylococcus } \\
\text { aureus }\end{array}$ & $\begin{array}{l}\text { Streptococcus } \\
\text { ssp }\end{array}$ & $\begin{array}{l}\text { Acinetobacter } \\
\text { Iwoffi }\end{array}$ & $\begin{array}{l}\text { Proteus } \\
\text { mirabilis }\end{array}$ & $\begin{array}{l}\text { Pseudomonas } \\
\text { aeruginosa }\end{array}$ & Total & P value \\
\hline Male & $10(35.7)$ & $13(46.4)$ & $2(7.1)$ & $0(0.0)$ & $1(3.6)$ & $2(7.1)$ & $28(100.0)$ & \\
\hline Female & $8(33.3)$ & $13(54.2)$ & $1(4.2)$ & $1(4.2)$ & $1(4.2)$ & $0(0.0)$ & $24(100.0)$ & .659 \\
\hline
\end{tabular}

* Chi-square test

Table 3: Bacterial prevalence per age category.

\begin{tabular}{|l|l|l|l|l|}
\hline & \multicolumn{3}{|c|}{ Presence of bacteria } & P value \\
\hline Age category & Yes & No & Total & \\
\hline $6-17$ years & $2(7.1)$ & $26(92.9)$ & $28(100.0)$ & \\
\hline $18-35$ years & $30(16.0)$ & $158(84.0)$ & $188(100.0)$ & \\
\hline $36-53$ years & $16(12.2)$ & $115(87.8)$ & $131(100.0)$ & .571 \\
\hline $54-70$ years & $4(17.4)$ & $19(82.6)$ & $23(100.0)$ & \\
\hline$>70$ years & $0(0.0)$ & $4(100.0)$ & $4(100.0)$ & \\
\hline
\end{tabular}

* Chi-square test

Table 4: Hand pathogen isolates of HCW and Patients

\begin{tabular}{|l|l|l|l|l|l|l|l|l|}
\hline $\begin{array}{l}\text { Type of } \\
\text { participant }\end{array}$ & CoNs & $\begin{array}{l}\text { Staphylococcus } \\
\text { aureus }\end{array}$ & $\begin{array}{l}\text { Streptococcus } \\
\text { ssp }\end{array}$ & $\begin{array}{l}\text { Acinetobacter } \\
\text { Iwoffi }\end{array}$ & $\begin{array}{l}\text { Proteus } \\
\text { mirabilis }\end{array}$ & $\begin{array}{l}\text { Pseudomonas } \\
\text { aeruginosa }\end{array}$ & Total & P value \\
\hline Patient & $10(34.5)$ & $16(55.2)$ & $2(6.9)$ & $1(3.4)$ & $0(0.0)$ & $0(0.0)$ & $29(100.0)$ & \\
\hline $\begin{array}{l}\text { Healthcare } \\
\text { provider }\end{array}$ & $8(34.8)$ & $10(43.5)$ & $1(4.3)$ & $0(0.0)$ & $2(8.7)$ & $2(8.7)$ & $23(100.0)$ & .275 \\
\hline
\end{tabular}

* Chi-square test 
Table 5: Hand pathogens isolates per age group category

\begin{tabular}{|l|l|l|l|l|l|l|l|l|}
\hline & \multicolumn{7}{|c|}{ Bacteria type } & Pcinetobacter \\
\hline Age Years & CoNs & S. aureus & $\begin{array}{l}\text { Streptococcus } \\
\text { ssp }\end{array}$ & $\begin{array}{l}\text { Proteus } \\
\text { mirabilis }\end{array}$ & $\begin{array}{l}\text { Pseudomonas } \\
\text { spp }\end{array}$ & Total & P value \\
\hline $6-17$ & 0 & 2 & 0 & 0 & 0 & 0 & 2 & 2 \\
\hline $18-35$ & 11 & 12 & 2 & 1 & 2 & 2 & 30 & \\
\hline $36-53$ & 7 & 8 & 1 & 0 & 0 & 0 & 16 & .810 \\
\hline $54-70$ & 0 & 4 & 0 & 0 & 0 & 0 & 4 & \\
\hline
\end{tabular}

*Chi-square test

Table 6: Staphylococcus aureus Susceptibility pattern among healthcare providers.

\begin{tabular}{|l|l|l|}
\hline & MSSA & MRSA \\
\hline Lab Tech & 2 & 0 \\
\hline Pharm Tech & 0 & 0 \\
\hline Nurses & 3 & 0 \\
\hline Doctors & 4 & 0 \\
\hline Allied Services & 1 & 0 \\
\hline Total & 10 & 0 \\
\hline
\end{tabular}

Table 7: Staphylococcus aureus Susceptibility pattern among Patients.

\begin{tabular}{|l|l|l|}
\hline Patients & MRSA & MSSA \\
\hline $6-17$ years & 0 & 2 \\
\hline $18-35$ years & 0 & 6 \\
\hline $36-53$ years & 2 & 4 \\
\hline $54-70$ years & 0 & 2 \\
\hline$>70$ years & 0 & 0 \\
\hline
\end{tabular}

Table 8: Antimicrobial sensitivity levels of $S$. aureus to different antimicrobial agents.

\begin{tabular}{|l|l|l|}
\hline Antimicrobial & Resistant $(\mathbf{N}=\mathbf{2 6})$ & Sensitive (N=26) \\
\hline Trimethoprim/Sulfamethoxazole & 7 & 19 \\
\hline Benzylpenicillin & 26 & 0 \\
\hline Erythromycin & 4 & 22 \\
\hline Clindamycin & 4 & 22 \\
\hline Vancomycin & 0 & 26 \\
\hline Tetracycline & 0 & 26 \\
\hline Levofloxacin & 0 & 26 \\
\hline Mupirocin & 0 & 26 \\
\hline Linezolid & 0 & 26 \\
\hline Gentamicin & 0 & 26 \\
\hline Nitrofurantoin & 0 & 26 \\
\hline Oxacillin & 2 & 24 \\
\hline Cefoxitin Screen & 2 & 24 \\
\hline
\end{tabular}




\section{Discussion}

Healthcare workers and Patient's hands were colonized with Staphylococcus aureus that dominates other possible pathogen. Coagulase negative staphylococci (CoNs) are common colonizer of human skin and comprises of several staphylococcal species. The CoNs isolated in these study included; Staphylococcus saprophyticus, Staphylococcus auricularis, Staphylococcus warnei, Staphylococcus epidermidis, Staphylococcus haemolyticus, Staphylococcus cohnii, Kocuria kristinae and Luconostoc pseudomesenteriodes. These was followed by Streptococcus species isolates which included Aerococcus viridans, Globicatella sanguinis and Granulicatella elegan, Acinetobacter lwoffi, Pseudomonas aeruginosa, Proteus mirabilis and Acinetobacter lwoffi. It was determined that the possible bacterial pathogens prevalence in outpatient centers was 14\% (52/374). Micrococcus luteus dominates the environmental contaminants on hand of both healthcare and patients followed closely by aerobic spore forming bacilli (ASBs) and fungi respectively. This study concurs with authors from India who reported $10 \%$ of potential pathogen growth and $0.7 \%$ methicillin resistant staphylococcus aureus. ${ }^{[13]}$

The determination of $S$. aureus hand carriage of healthcare providers and Patients visiting outpatient healthcare facilities offer a clear comparative in this study. The study found $6.9 \%$ (26/374) overall hand prevalence of Staphylococcus aureus among healthcare providers and Patients. The study further, found 8.0\% (10/124) of health care workers' hands had been colonized with $S$. aureus while Patients had 6.4\% (16/250). This study was in agreement with a similar in prevalence of hand carriage rate of $8.9 \%$ reported by Aiken ${ }^{[2]}$ at Thika level 5 Hospital among inpatients and although it is lower than $15.0 \%$ reported by Mogere ${ }^{[14]}$ at Kenyatta National Hospital on hands of HCW which is a public referral healthcare institution. However, this study was not comparable to the study done in S. Africa by Matuka ${ }^{[10,15]}$ which had higher prevalence of 41\% (29/70) Staphylococcus aureus hand carriage among staffs in surgical theatres from chosen hospitals in Johannesburg, South Africa due to lower number of participants and the methods employed which in case was conventional techniques for sample analysis. Similarly, further higher prevalence rate in India of $41.7 \%(25 / 60)$ reported in $\mathrm{HCW}$ working at ICU in tertiary healthcare facility by Mathew. ${ }^{[16]}$ In Egypt the study by Elshabrawy ${ }^{[9]}$ revealed 29.9\% (70/234) of healthcare workers were colonized with staphylococcus aureus on their nostrils.

Bacteriological colonization among the healthcare provider in this study showed a significant relationship on increased chances infections by $\mathrm{HCW} P$ value 0.049 than patient. The key point of this finding that informs the concern of strictly adherence of hand washing protocols by healthcare providers. The study agrees with previous studies conducted by Joachim ${ }^{[17]}$ on $S$. aureus at regional hospital in Dares Salaam, Tanzania that suggested male had $11.1 \%$ and female had $6.7 \%$ risk of acquiring MRSA.

The Staphylococcus aureus isolated on healthcare provider's hand were all sensitive to Oxacillin and Cefoxitin antimicrobial agent. The perceived reduction in resistance may be attributed to a well-established infection prevention and control (IPC) mechanism in tertiary hospital and outreach satellites. This research also echoes the report presented by Prabhu ${ }^{[6]}$ on HCW at ICU of tertiary care hospital that show no staphylococcus aureus resistance among healthcare workers. The $S$. aureus isolates were all resistant to benzylpenicillin and significant number to Trimethoprim.

The overall methicillin resistant Staphylococcus aureus prevalence rate of isolates had $0.53 \%$ (2/374) showed resistance to both Oxacillin and Cefoxitin on the hands of healthcare attendants and those visiting at outpatient healthcare facilities. The community MRSA alone had the prevalence of $0.8 \%(2 / 250)$ that had colonized patient's hands in this study. Community methicillin resistant Staphylococcus aureus being reported here shows low rate than other published elsewhere. This result showed lower magnitude than previous studies contacted in same institution of 3.7\% (27/731) by Omuse ${ }^{[11]}$ which reported from pus swab of patients with skin and soft tissue infection at AKUHN and Gertrude children hospitals. Also notable prevalence 6.9\% that was revealed by Aiken ${ }^{[2]}$ at Thika level five in Kiambu County. The result shows a lower prevalence as compared to several authors in African countries. Notably, reports published on MRSA hand carriage in Egypt showed slight higher rate of $8.6 \%$ by Elishabrawy. ${ }^{[9]}$ Elsewhere $6.67 \%$ MRSA hand carriage was documented in India by Mathew ${ }^{[16]}$ on healthcare care worker in ICU facility in a tertiary care hospital.

However, the MRSA microbes obtained here were sensitive to Vancomycin, Linezolid, Levofloxacin, Gentamycin, Nitrofurantoin, tetracycline and Mupirocin. The all staphylococcus aureus isolates had shown resistance to benzylpenicillin 100\% followed closely by Trimethoprim/ Sulfamethoxazole at 73\%, Erythromycin and clindamycin both at $15.3 \%$ respectively. The later resistance to Erythromycin and clindamycin was comparable to the earlier reported by Omuse ${ }^{[11]}$ at $11.7 \%$ and $10 \%$ respectively. 


\section{Conclusion}

The burden of transient pathogen is still of concern especially at outpatient facilities and community through contaminated hands. The study concludes that $14 \%$ of the hands of healthcare and patients at Aga Khan University Hospital outreach centres were colonized with possible pathogens. Healthcare providers pose a higher risk of being colonized by multi-resistant pathogens than the patient $p$ value 0.049 however staphylococcus aureus showed susceptible to oxacillin and cefoxitin at these outpatient facilities. The community MRSA rate in our study was $0.53 \%$ in patients and healthcare workers. All S. aureus isolates from hands of participants showed resistance to Benzyl penicillin anti-microbial agent. The two community MRSA isolates were sensitive to other antimicrobial agents such as Vancomycin, Linezolid, Mupirocin, Levofloxacin, Gentamycin, Nitrofurantoin and tetracycline. The strategies to combat the antimicrobial resistance in outpatient should be stepped up to enhance rationale use of antibiotics. Regular hand washing and use of alcohol based product still remains key in infection prevention and control of hand carriage in public and private facilities.

\section{Acknowledgements}

The most gratitude also goes to German Research Foundation for funding this study. Further appreciation is extended to all staffs of AKUHN Outreach Centres and the microbiology laboratory department staffs for technical support.

\section{Funding}

This project was funded by -DFG grant

ZI-665/3-0(20028-2022).

Principal Investigator-Gunturu Revathi of Aga Khan

University, Nairobi.

\section{Competing Interests}

All authors declare that they have no competing interest.

\section{Reference}

1. Musu, M., Lai, A., Mereu, N. M., Galletta, M., Campagna, M., Tidore, M., Colombo, S. (2017). Assessing hand hygiene compliance among healthcare workers in six Intensive Care Units. Journal of preventive medicine and hygiene, 58(3), E231.

2. Aiken, A. M., Mutuku, I. M., Sabat, A. J., Akkerboom, V., Mwangi, J., Scott, J. A. G., Grundmann, H. (2014). Carriage of Staphylococcus aureus in Thika Level 5 Hospital, Kenya: a cross-sectional study. Antimicrobial resistance and infection control, 3(1), 22.

3. Dancer, S. J. (2014). Controlling Hospital- Acquired Infection: Focus on the role of the Environment and the new technology for decontamination. Clinical Microbiology Review, 27(4), 665-690.
4. Ataee, R. A., Ataee, M. H., Tavana, A. M., \& Salesi, M. (2017). Bacteriological aspects of hand washing: A key for health promotion and infections control. International journal of preventive medicine, 8 .

5. Belkum, A. V., \& Rochas, O. (2018). Laboratory-based abd point of care testint for MSSA/MRSA detectionin the age of whole genome sequencing. Frontiers in microbiology, 9(1437).

6. Prabhu, M., Sugumari, C., \& Pranesh, G. (2017). Bacteriological profile of health workers hands working in various ICUs of a tertiary care hospital. Global journal for research analysis, 6(5).

7. Russotto, V., Cortegiani, A., Raineri, S. M., P. Iozzo, Gregoretti, C., \& Giarratano, A. (2017). What is the risk of acquiring bacteria from prior intensive care unit bed occupants?. Critical Care, 21(1), 55-62.

8. David, M. Z., Siegel, J. D., Henderson, J., Leos, G., Lo, K., Iwuora, J., Boyle-Vavra, S. (2014). Hand and nasal carriage of discordant Staphylococcus aureus isolates among urban jail detainees. Journal of clinical microbiology, 52(9), 34223425 .

9. Elshabrawy, W. O., Zaki, M. E., \& Kamel, M. F. (2017). Genetic and phenotypic study of methicillin-resistant Staphylococcus aureus among patients and health care workers in Mansoura University Hospital, Egypt. Iranian journal of microbiology, 9(2), 82.

10. Matuka O, Binta B, Carman A, \& Singh T. (2018). Staphylococcus aureus and Escherichia coli levels on the hand of theatre staff. Creative Common Licence CC-BYNC, 108(6).

11. Omuse, G., Kabara, B., \& Revathi., G. (2014). Low Prevalence of methicillin resistant Staphylococcus aureus determine by an automated identification system Biomedcentral infectious diseases, 14(669).

12. Karaaslan, A., Kepenekli Kadayifci, E., Atıc1, S., Sili, U., Soysal, A., Çulha, G., Bakır, M. (2014). Compliance of healthcare workers with hand hygiene practices in neonatal and pediatric intensive care units: overt observation. Interdisciplinary perspectives on infectious diseases, 2014.

13. Visalachy, S., Palraj, K. K., Kopula, S. S., \& Sekar, U. (2016). Carriage of Multidrug Resistant Bacteria on Frequently Contacted Surfaces and Hands of Health Care Workers. Journal of clinical and diagnostic research: JCDR, 10(5), DC18-DC20.

14. Mogere, Alex W (2015). Carriage rate of methicillin resistant staphylococcus aureus among health care workers at The Kenyatta National Hospital. http:/hdl.handle. net/11295/94041

15. Sousa, A. M.; Pereira, M. O., 2013. A prospect of current microbial diagnosis methods. In A. Mendez-Vilas, Microbial Pathogens and Strategies for Combating Them: Science, Technology and Education, Vol. 3, ISBN: 978-84-942134$1-0,1429-1438$ 
16. Mathew, R. S., Ambica, R., \& Shantala, G. B. (2017). Study of Bacteriological Profile on Hands of Health Care Workers in ICU Setup in a Tertiary Care Hospital. International Journal of Current Microbiology and Applied Sciences (IJCMAS), 6(12), 2698-2702.
17. Joachim, A., Moyo, S. J., Nkinda, L., Majigo, M., Mbaga, E., Mbembati, N. et al. Lyamuya, E. F. (2017). Prevalence of methicillin-resistant Staphylococcus aureus carriage BioMed Central research notes, 10(417).

*Corresponding author:

Martin Wanyama, Mount Kenya University

Phone: +254721252905

Email: rhombosha1@gmail.com

Financial or other Competing Interests: None.

Date of Submission $\quad: 04 / 02 / 2020$

Date of Final Revision : 02/03/2021

Date of Acceptance $\quad: 08 / 03 / 2021$

Date of Publication $\quad: 30 / 03 / 2021$ 